\title{
Maps and Photographs
}

\section{Maps}

1 Southeast Asia during the Vietnam War 8

2 Saigon circa 1966-67 127

3 Warsaw, December 1966

4 Hanoi, December 1966

\section{Photographs}

Janusz Lewandowski: A Very Serious Fellow The Saigon Peace Plotters

Following page 280

The Action in Warsaw-and Hanoi

The Washington Policymakers

Following page 410

Looking Back

Following page 622 
